\title{
Review Article \\ The Renin-Angiotensin-Aldosterone System in Vascular Inflammation and Remodeling
}

\author{
Maricica Pacurari, ${ }^{1,2}$ Ramzi Kafoury, ${ }^{1,2}$ Paul B. Tchounwou, ${ }^{1,2}$ and Kenneth Ndebele ${ }^{1,2}$ \\ ${ }^{1}$ Biology Department, College of Engineering, Science, and Technology, Jackson State University, Jackson, MS 39217, USA \\ ${ }^{2}$ NIH RCMI-Center for Environmental Health, College of Engineering, Science, and Technology, \\ Jackson State University, Jackson, MS 39217, USA \\ Correspondence should be addressed to Maricica Pacurari; maricica.pacurari@jsums.edu
}

Received 16 January 2014; Revised 28 February 2014; Accepted 3 March 2014; Published 6 April 2014

Academic Editor: Jean-Marc Cavaillon

\begin{abstract}
Copyright (C) 2014 Maricica Pacurari et al. This is an open access article distributed under the Creative Commons Attribution License, which permits unrestricted use, distribution, and reproduction in any medium, provided the original work is properly cited.
\end{abstract}

\begin{abstract}
The RAAS through its physiological effectors plays a key role in promoting and maintaining inflammation. Inflammation is an important mechanism in the development and progression of CVD such as hypertension and atherosclerosis. In addition to its main role in regulating blood pressure and its role in hypertension, RAAS has proinflammatory and profibrotic effects at cellular and molecular levels. Blocking RAAS provides beneficial effects for the treatment of cardiovascular and renal diseases. Evidence shows that inhibition of RAAS positively influences vascular remodeling thus improving CVD outcomes. The beneficial vascular effects of RAAS inhibition are likely due to decreasing vascular inflammation, oxidative stress, endothelial dysfunction, and positive effects on regeneration of endothelial progenitor cells. Inflammatory factors such as ICAM-1, VCAM-1, TNF $\alpha$, IL-6, and CRP have key roles in mediating vascular inflammation and blocking RAAS negatively modulates the levels of these inflammatory molecules. Some of these inflammatory markers are clinically associated with CVD events. More studies are required to establish long-term effects of RAAS inhibition on vascular inflammation, vascular cells regeneration, and CVD clinical outcomes. This review presents important information on RAAS's role on vascular inflammation, vascular cells responses to RAAS, and inhibition of RAAS signaling in the context of vascular inflammation, vascular remodeling, and vascular inflammation-associated CVD. Nevertheless, the review also equates the need to rethink and rediscover new RAAS inhibitors.
\end{abstract}

\section{Renin-Angiotensin-Aldosterone System (RAAS) and Cardiovascular Disease}

The rennin-angiotensin-aldosterone system (RAAS), one of the most important hormonal systems, oversees the functions of cardiovascular, renal, and adrenal glands by regulating blood pressure, fluid volume, and sodium and potassium balance [1]. The classical RAAS system was discovered more than a century ago, and in 1934 Goldblatt et al. showed a Renin link between kidney function and blood pressure [2]. Since then, extensive experimental studies have been undertaken to identify the components of the RAAS and its role in regulating blood pressure. Abnormal activity of the RAAS leads to the development of an array of cardiovascular diseases (CVD; hypertension, atherosclerosis, and left ventricular hypertrophy), cardiovascular events (myocardial infarction, stroke, and congestive heart failure), and renal disease [1]. As early as in 1956, Leonald T. Skeggs suggested the development of drugs to regulate renin-angiotensinsystem (RAS), and since then an array of inhibitors have been developed. Due to RAAS signaling pathways complexity than previously thought, half-century later, new RAAS inhibitors are still being developed [3]. Indeed, numerous experimental and clinical evidences indicate that pharmacological inhibition of RAAS with angiotensin-converting enzyme inhibitors (ACEIs), angiotensin receptor blockers (ARBs), direct rennin inhibitors (DRIs), and mineralocorticoid receptor antagonists (MRAs) is effective in treating hypertension and diabetic renal injury, and the results show a reduction in CVD and heart-related events worldwide [1]. This review 
discusses recent findings in our understanding of the role of RAAS components and their inhibition effects on vascular inflammation, vascular remodeling, and CVD.

1.1. RAAS. Renin, an active proteolytic enzyme, is first synthesized as an inactive preprohormone (prorenin), undergoes subsequent proteolytic changes in the afferent arterioles of renal glomerulus, and then is released into circulation [4]. In the circulation, proteolytic and nonproteolytic mechanisms cleave prorenin to the active renin. Active renin acts upon its substrate, angiotensinogen, to generate angiotensin I (Ang I). Ang I is cleaved by angiotensin-converting enzyme (ACE) resulting in physiologically active angiotensin II (Ang II). Ang II, the main effector of the RAAS, mediates its effects via type 1 Ang II receptor (AT1R). However, few studies suggest the existence of additional receptors for prorenin and renin in the heart, kidney, liver, and placenta [5]. Other studies suggest the presence of renin receptors in visceral and subcutaneous adipose tissues suggesting a local production of Ang II. Activation of prorenin and renin receptors stimulates mitogen activated kinase (MAPK)/extracellular signal-regulated kinase (ERK1/2) related signaling pathway [6]. Since the ratelimiting step of RAAS is under the control of renin, the idea of inhibiting renin to suppress RAAS was suggested in the mid1950s, but the development of rennin inhibitors was a long and difficult process [7]. Likewise, the first oral DRI, aliskiren, was marketed in 2007 for the treatment of hypertension [8]. Another effector of the RAAS, aldosterone, exerts important endocrine functions by regulating fluid volume, sodium and potassium homeostasis, and primarily acting in the renal distal convoluted tubules. Aldosterone mediates genomic and nongenomic effects via mineralocorticoid receptor (MR), AT1R, G-protein-coupled receptor, and epidermal growth factor receptors (EGFR). Downstream effectors of these receptors such as MAPK/ERK1/2/p38 pathways mediate vascular biology and physiology, particularly, vascular remodeling, inflammation, fibrosis, and vascular tone. Aldosterone's cardiopathological effects include myocardial fibrosis and hypertrophy and vascular remodeling and fibrosis. Production of aldosterone is under the regulation of angiotensin II, hyperkalemia, adrenocorticotropic hormone (ACTH), and sodium level [9]. Clinical trials have shown that blocking aldosterone receptors with mineralocorticoid receptor antagonists (MRA), spironolactone or eplerenone, reduces blood pressure, lowers albuminuria, and improves the outcome of patients with heart failure or myocardial infarctions or cardiovascular complications associated with diabetes mellitus [10]. Aldosterone infusion in an ischemia animal model induces vascular changes via AT1R, since blocking AT1R inhibited aldosterone effects, indicating cross-talk among RAAS components.

The recent discovery and cloning of a new angiotensin converting enzyme, ACE2, has introduced further complexity to RAAS. ACE2 is $42 \%$ homolog to ACE1 and is expressed in the heart, kidney, testis, endothelium of coronary, intrarenal vessels, and renal tubular epithelium [11]. ACE2 is a monopeptidase with enzymatic preference for hydrophobic/basic residues of Ang II C-terminus that leads to the formation of angiotensin II (1-7). Experimental studies show that Ang II (1-7) is a competitor of Ang II and indeed may have cardiorenal protective effects $[12,13]$. Ang II is also produced by non-ACE enzymes, such as serine protease chymase, which have been found in the heart, vasculature, and other tissues $[14,15]$.

\section{Inflammation and Cardiovascular Disease}

Inflammation plays a key role in the initiation, progression, and development of an array of cardiovascular diseases such as hypertension, atherosclerosis, restenosis after balloon angioplasty, nephropathy, and cardiomyopathy [16]. A typical example of how inflammation underlies the development of cardiovascular disease is atherosclerosis, via the activation of endothelial cells by the inflammatory cytokines. Endothelium dysfunction due to injury by the inflammatory process has been associated with cardiovascular risk factors including hypertension, diabetes mellitus, or obesity [17].

2.1. Markers of Inflammation. Tumor necrosis factor alpha $(\mathrm{TNF} \alpha)$ is a key proinflammatory cytokine regulating the expression of many genes of inflammation, oxidative stress, and antiapoptotic signaling pathways, virtually, in all types of cells [18]. Aberrant TNF $\alpha$ signaling leads to the development of pathological conditions including cardiovascular disease, and therapeutic blocking of $\mathrm{TNF} \alpha$ signaling has been proposed for the treatment of several inflammatory diseases particularly rheumatoid arthritis and bowel disease [18]. TNF $\alpha$ impairs endothelium-dependent nitric oxide (NO) mediated vasorelaxation in coronary arteries or carotid artery via superoxide radical production [19]. Patients with high levels of circulating TNF $\alpha$ have a greater risk of developing cardiovascular disease [20]. In endothelial cells, TNF $\alpha$ induces the expression of interleukin-6 (IL6), monocyte chemoattractant protein-1 (MCP-1), and cell adhesion molecules (CAM) [21]. Deletion of TNF $\alpha$ in mice inhibits intimal hyperplasia after carotid artery injury [22], while an increased expression of TNF $\alpha$ aggravates pulmonary hypertension in mice [23]. TNF $\alpha$ mediated inflammation plays an important role in vascular remodeling. Human carotid artery smooth muscle cells respond to TNF $\alpha$ with increased cell proliferation, whereas inhibition of circulating $\mathrm{TNF} \alpha$ prevents carotid artery postinjury media remodeling and neointima formation in rats [24]. TNF $\alpha$ inhibition has been shown to improve endothelium function via stimulating endothelial cells regeneration [25].

$\mathrm{NF}-\kappa \mathrm{B}$, a proinflammatory factor downstream of $\mathrm{TNF} \alpha$, plays a central role in regulating the expression of vascular inflammatory mediators interleukin-1 beta (IL-1 $\beta$ ), interleukin-6 (IL-6), TNF $\alpha$, and MCP-1 in endothelial cells and other cell types [26]. Activated NF- $\kappa$ B induces vascular smooth muscle cells proliferation and mediates neointima hyperplasia after vascular injury [27].

Another marker of inflammation is C-reactive protein (CRP). CRP is considered a hallmark of the acute-phase response and a predictor of cardiovascular event risk [28]. C-reactive protein is mainly produced in the liver [29], but other cell types such as smooth muscle and endothelial cells 
of atherosclerotic arteries show CRP expression [30]. CRP plays a role in mediating vascular disease. In vitro studies show that CRP has proinflammatory and prothrombotic effects [31], inhibits endothelial progenitor cell differentiation and function [32], and upregulates AT1R [33]. CRP activates classical complement signaling cascade, which plays a key role in neointima formation in injured vessels [34]. Circulating CRP levels correlate with several inflammation markers including inflammatory cytokines, cell adhesion molecules, markers of activated platelets, and white cells [35]. All of these inflammation markers are also predictive of coronary artery events [36].

Interleukin-6, a pleiotropic cytokine, regulates many cellular functions including proliferation and apoptosis. IL6 plays an important role in inflammation and modulates the development of several diseases including cardiovascular disease such as hypertension and other related diseases. High circulating levels of IL- 6 are found in hypertensive patients. Type I diabetic rats have high circulating levels of IL- 6 and increased blood vessel contractility [37]. IL-6 overexpression in mice induces pulmonary vascular remodeling that is similar to that seen in patients with pulmonary hypertension and induces pulmonary hypertension via proliferative and antiapoptotic mechanisms [38]. IL-6 also modulates vascular reactivity. Treatment of isolated human blood vessels from various organs with IL-6 results in increased contraction [39]. IL-6 mediates the development of vascular occlusive disease and is a predictor of cardiovascular sudden death [40]. IL-6 effects on vascular system are mediated via NF- $\kappa \mathrm{B}$ signaling, which plays a key role in vascular remodeling. Inhibition of $\mathrm{NF}-\kappa \mathrm{B}$ via deletion of $\mathrm{I} \kappa \mathrm{BNS}$, a nuclear $\mathrm{I} \kappa \mathrm{B}$ regulatory protein of NF- $\kappa \mathrm{B}$, reduces intimal hyperplasia after vascular injury in mice via NF- $\kappa$ B-mediated IL-6 production [41].

2.2. Intercellular Adhesion Molecules. Inflammation-mediated injury to endothelium generates a pronflammatory signaling cascade and the expression of intercellular adhesion molecule-1 (ICAM-1) and vascular cell adhesion molecule1 (VCAM-1), both of which recruit blood monocytes to vascular wall, thus perpetuating the release of more cytokines and chemokines at injury site culminating with development of vascular disease such as atherosclerosis. Circulating levels of ICAM-1 and VCAM-1 positively correlate with carotid intima-media ratio [42]. VCAM-1 expression is upregulated by Ang II in rat aorta, whereas spironolactone, an antagonist of mineralocorticoid receptors, inhibits VCAM-1 and other inflammatory markers expression [43]. Treatment of endothelial cells with Ang II upregulates VCAM-1 via oxidative stress and NF- $\kappa$ B activation [44]. High circulating levels of ICAM-1, VCAM-1, and other inflammatory cell adhesion molecules are associated with left ventricle hypertrophy $(\mathrm{LVH})$ and diastolic dysfunction in aged population [45].

\section{RAAS and Vascular Inflammation}

RAAS plays a crucial role in the initiation and maintenance of vascular inflammation and vascular remodeling. Vascular inflammation leads to endothelium dysfunction, and a decreased endothelial function mediates progression of cardiovascular disease. A dysfunctional endothelium is leaky and facilitates migration of inflammatory cell into the vascular wall and stimulates smooth muscle cells proliferation, processes that decrease vascular function and promote development of cardiovascular disease and tissue injury. A dysfunctional endothelium provides proinflammatory environment in such as it promotes recruitment and attachment of inflammatory cells, which are well known to play a key role in atherosclerosis. There is increasing evidence indicating a link between hypertension and atherosclerosis via Ang II mediated inflammation. In vivo, acute treatment with Ang II significantly increases leukocytes adhesion in the rat mesenteric arteries [46]. Animal and human studies show that Ang II has proinflammatory responses in arteries, heart, and kidney by regulating the expression of cytokines and chemokines. In human vascular smooth muscle cells, Ang II induces NF- $\kappa \mathrm{B}$ activation and the expression of IL-6 [47], MCP-1, and TNF $\alpha$ in monocytes [48]. In vivo infusion of Ang II causes increased expression of VCAM-1 in rat aorta via NF- $\kappa$ B transcriptional activation. Administration of losartan, an AT1R antagonist, inhibits Ang II-induced NF- $\kappa$ B activation and VCAM-1 accumulation [49]. In vitro treatment of rat vascular smooth muscle cells with Ang II upregulates MCP-1, and blockade of AT1R with losartan prevents MCP1 expression and monocytes migration into vessel wall and other target organs [50]. Although a vasoconstrictor, Ang II induces endothelial damage by inhibiting endothelial cells regeneration. Ang II acts as a second messenger to activate intracellular signaling pathways such as mitogen-activated protein kinase (MAPK) and AKT, pathways that mediate cell proliferation and apoptosis and thereby vascular dysfunction [51]. Ang II plays a significant role in the initiation and progression of atherogenesis, an inflammation mediated process. In injured arteries, Ang II provides a positive feedback loop in vascular inflammation via recruitment of inflammatory cells, which then produce more Ang II, therefore perpetuating vascular inflammation [1]. Ang II is a potent prooxidant. Ang II induces the production of superoxide anions and activates the prooxidant NADH/NADPH signaling [52]. Ang II-mediated oxidative stress reduces nitric oxide (NO) level and activates redox sensitive genes, particularly cytokines, adhesion molecules, and matrix metalloproteinases [53]. Ang II is also a profibrotic factor. Chronic infusion of mice with Ang II results in increased blood pressure, infiltration of inflammatory cells into myocardium, and cardiac fibrosis [54]. In rat cardiomyocytes, Ang II induces calcium signals $\left(\mathrm{Ca}^{2+}\right)$ and oxidative stress, which cooperatively induce cardiomyocytes hypertrophy [55]. Chronic treatment of rat aortic smooth muscle cells with Ang II induces cell hypertrophy by increasing protein synthesis [56]. Ang IItreated rat cardiac fibroblasts display increased expression of focal adhesion kinases (FAK) and integrins, whereas cardiac myocytes express high levels of c-fos, EGFR1, TGF $\beta$, and extracellular matrix proteins $(109,110)$. Inflammation mediates endothelial injury which alters endothelial cell architecture so that the endothelium becomes dysfunctional. It has been shown that a dysfunctional endothelium is directly 
associated with hypertension and atherosclerosis [17]. A functional endothelium is a key regulator of NO release, and loss of NO bioavailability is associated with high level of Ang II via oxidative stress. Although development of atherosclerosis is a multifactorial complex process, interaction between endothelial dysfunction and oxidative stress plays an important role in atherosclerotic process. Increased oxidative stress within the vascular wall is a hallmark of vascular disease such as atherosclerosis, hypertension, and diabetes. Indeed, high level of superoxide is an important factor in atherosclerosis initiation by recruitment of inflammatory cells and endothelial dysfunction. Total genetic deletion of NADPH oxidase subunit, Nox2, in mice results in significant decrease of aortic atherosclerosis [57]. Blocking RAAS with valsartan in combination with fluvastatin (a statin) in atherosclerosis mouse model, the apolipoprotein $\mathrm{E}\left(\mathrm{ApoE}^{-} /^{-}\right)$null mice, reduces the level of atherosclerotic lesions, superoxide anion, and the expression level of MCP1 and ICAM-1, indicating that blocking inflammation and oxidative stress has beneficial effects on endothelium [58]. Indeed, clinical studies show a reduction in cardiovascular events beyond blood pressure lowering such as positively altering endothelium/vascular wall structure which in turn mediates reduction of cardiovascular disease. Several RAAS inhibitors such as ACEI ramipril and ARB losartan improve endothelial activity and vascular function by increasing $\mathrm{NO}$ bioavailability [17]. NO has protective effects on cardiovascular and renal systems. NO effects on the vasculature are numerous from inducing vasodilatation of all types of blood vessels to inhibiting platelet aggregation and adhesion or leukocytes adhesion to endothelium. Furthermore, NO inhibits DNA synthesis, mitogenesis, and vascular smooth muscle cells proliferation and counteracts oxidative stress [59]. NO bioavailability depends on the activity of eNOS, and a diminished eNOS activity is associated with essential hypertension [59].

The proinflammatory and profibrotic effects of the RAAS are also mediated by aldosterone. Aldosterone plays a role in organ fibrosis and tissue ischemia, and in conjunction with macrophages, it induces cardiac fibrosis [60]. Aldosterone promotes insulin resistance and vascular remodeling and influences the development of atherosclerosis [61]. In vascular smooth muscle cells, aldosterone alters insulin signaling by upregulating the expression of insulin-like growth factor-1 receptor (IGF1R) and hybrid receptor and modulates membrane structure via tyrosine kinase receptors [62]. Chronic infusion of aldosterone induces oxidative stress in rat aorta, and MR antagonist spironolactone reduces reactive oxygen species generation [62]. Animal studies also indicate an association between aldosterone and decreased $\mathrm{NO}$ synthesis and endothelial progenitor cells (EPC) via oxidative stress and low levels of VEFGR2 [63]. NO plays a key role in vascular homeostasis through its effects on endothelial and smooth muscle cells. In endothelial cells, NO potentiates VEFG mitogenic effects, thereby stimulating endothelial cells proliferation. In VSMC, NO limits their proliferation and migration [64]. In addition to RAAS present in systemic circulation and its production in local tissues, there are also reports about the identification of an intracellular
RAAS in certain cell types such as hepatoma cells [65], renal cortical cells [66], or adrenal medullary chromaffin and pituitary glandular cells [67]. Human and rat adrenal cortical cells stimulated with Ang II produce aldosterone via AT1R-upregulation of cytochrome P450 oxidase B2 and increased level of hydrogen peroxide, whereas pretreatment with losartan and antioxidants abrogates Ang II effects [68]. As shown in Figure 1, Ang II, the master cytokine, TNF $\alpha$, and aldosterone induce the expression of a myriad of molecular effectors of signaling pathway associated with vascular inflammation and remodeling, fibrosis, and oxidative stress. Several molecular molecules such as ERK1/2 and NADPH are also activated by Ang II and aldosterone and activate NF- $\kappa \mathrm{B}$-dependent signaling in the absence of $\mathrm{TNF} \alpha$, crosstalk that indicates the complexity of RAAS effectors role in mediating vascular inflammation and remodeling (Figure 1). Moreover, the cross-talk between Ang II and aldosterone indicates the intricacy of the RAAS system on cardiovascular system pathology.

\section{RAAS Blockers and Vascular Inflammation}

Blocking RAAS signaling either with ACEIs which inhibit the formation of angiotensin, or ARBs which block angiotensin receptors, or DRIs which inhibit the renin-angiotensinogen reaction, or MRAs which block aldosterone, alone or in combinations, reduces mortality and morbidity in diabetes, hypertension, atherosclerosis, heart failure, and stroke [69]. The multiple biological and physiological effects as a result of RAAS inhibitors are summarized in Table 1 and include decreased inflammation, vascular remodeling, and fibrosis, oxidative stress, increased endothelial function and nitric oxide, and maintenance of bradykinin and endotheliumderived hyperpolarizing factors (EDHF), both of which contribute to maintenance of vascular tone. However, blockade of the RAAS at one level is not very effective to treat hypertension; therefore blocking RAAS at multiple levels seems to provide clinical efficacy for the treatment of hypertension and other forms of cardiovascular disease including atherosclerosis [69].

4.1. Direct Renin Inhibitors (DRIs). DRIs block RAAS by inhibiting renin enzymatic activity. A recently approved DRI, aliskiren, is an oral direct renin inhibitor that lowers blood pressure by blocking the rate-limiting step of the RAAS. In a randomized double-blinded trial study, Andersen et al. [70] and others [71] reported that aliskiren-based therapy lowered blood pressure (BP) and plasma renin activity (PRA), and the effects persisted over four weeks, suggesting long term effects of aliskiren on renin activity. However, plasma renin activity can be increased by ACEIs or ARB; therefore combination of aliskiren with ACEIs or ARBs has been considered as a preferred option of treatment of hypertension, congestive heart failure, and chronic kidney disease [72]. Aliskiren has beneficial effects on endothelium. In patients with type I diabetes, aliskiren improved endothelial function independently of lowering blood pressure. In an atherosclerosis transgenic 


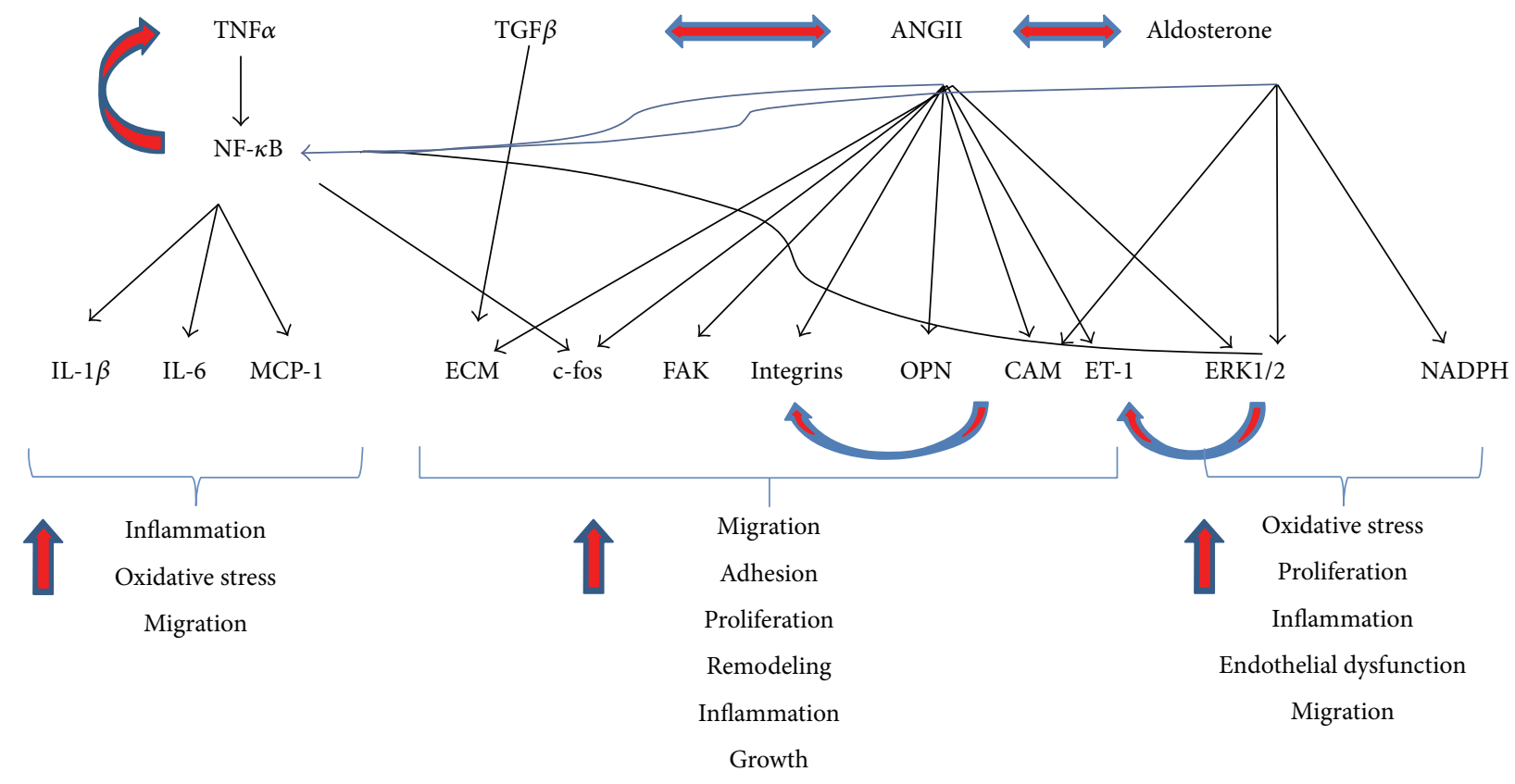

FIGURE 1: Schematic representation of various molecular factors activated by RAAS effectors and cross-talk between RAAS effectors and molecular factors involved in signaling pathways with role in vascular inflammation and remodeling. Double arrow: cross-talk; single arrow: increased expression or stimulation.

TABLE 1: Pharmacological effects of RAAS inhibitors on cardiovascular function.

\begin{tabular}{|c|c|c|c|c|c|c|}
\hline DRI & ACEI & $\mathrm{ARB}$ & MRB & Ang 1-7 & ASI & (P)RRI \\
\hline $\begin{array}{l}\downarrow \text { Cardiac } \\
\text { hypertrophy }\end{array}$ & $\begin{array}{c}\uparrow \text { Endothelial } \\
\text { function }\end{array}$ & $\begin{array}{l}\uparrow \text { Endothelial } \\
\text { function }\end{array}$ & $\downarrow$ Heart attack & Vasodilation & $\begin{array}{l}\downarrow \text { Blood } \\
\text { pressure }\end{array}$ & \\
\hline$\downarrow$ Blood pressure & $\uparrow \mathrm{NO}$ & $\downarrow$ Inflammation & $\downarrow$ Blood pressure & $\downarrow$ Proliferation & & \\
\hline $\begin{array}{l}\uparrow \text { Endothelial } \\
\text { Function }\end{array}$ & - Bradikynin & $\downarrow$ Oxidative stress & $\downarrow$ Inflammation & $\downarrow$ Cardiac fibrosis & $\begin{array}{l}\downarrow \text { Cardiac } \\
\text { remodeling }\end{array}$ & $\begin{array}{l}\downarrow \text { Cardiac } \\
\text { fibrosis }\end{array}$ \\
\hline $\begin{array}{l}\downarrow \text { Monocytes } \\
\text { Adhesion }\end{array}$ & $\begin{array}{l}\downarrow \text { Vascular } \\
\text { remodeling }\end{array}$ & $\downarrow$ Cardiac fibrosis & $\downarrow$ Atherosclerosis & $\downarrow$ Hypertrophy & $\begin{array}{c}\downarrow \text { Cardiac } \\
\text { hyperthrophy }\end{array}$ & $\begin{array}{c}\downarrow \text { Retinal } \\
\text { inflammation }\end{array}$ \\
\hline$\downarrow$ Inflammation & - EDHF & $\begin{array}{l}\downarrow \text { Vascular } \\
\text { remodeling }\end{array}$ & & $\begin{array}{l}\downarrow \text { Vascular } \\
\text { remodeling }\end{array}$ & & \\
\hline \multicolumn{7}{|l|}{$\begin{array}{l}\downarrow \text { Vascular intima } \\
\text { hypertrophy }\end{array}$} \\
\hline$\downarrow$ Oxidative stress & & & & & & \\
\hline
\end{tabular}

ACEI: angiotensin-converting enzyme inhibitors; ARB: type 1 Ang II receptor blockers; MRB: mineralcorticoid receptor blockers; DRI: direct rennin inhibitors; NO: nitric oxide; EDHF: endothelium derived hyperpolarizing factor. Thin arrow: increased or decreased; bullet: maintenance of the level.

mouse model, aliskiren alone or in combination with atorvastatin inhibited atherosclerosis development and plaque progression via decreasing monocytes adhesion and MCP-1 levels [73]. In eNOS deficient mice, aliskiren prevented cardiac hypertrophy, inflammation, coronary artery remodeling, and vascular intimal hyperplasia, and even greater effects were found in combination with valsartan. Mechanistically, aliskiren and valsartan combination downregulates NADPH oxidase activity and therefore attenuates oxidative stress [59], which plays a key role in initiating the development of vascular inflammation and cardiovascular disease.

4.2. (Pro)renin Receptor and Potential Inhibitors. (Pro)renin receptor (P)RR discovery in 2002 has shed light on tissue renin-angiotensin system and function of circulating prorenin, the inactive precursor of renin. Prorenin and renin have been shown to bind (P)RR with high affinity; however, prorenin exhibits higher affinity for (P)RR, an indication that indeed prorenin might be the actual ligand for $(\mathrm{P}) \mathrm{RR}$. Studies have shown that upon prorenin binding and activation of (P)RR, downstream signaling results in the activation of MAPK ERK1/2/p38 and Akt in a variety of cells, including VSMC [74]. The role of (P)RR in cardiovascular pathology proved to be more difficult to study than thought, since genetic deletion of (P)RR in mice is lethal or life-span is very short, making functional analysis of this receptor almost impossible to study and also suggesting that there is a need of normal 
level of (P)RR for homeostasis. However, several studies focused on (P)RR role in cardiovascular complications mediated by diabetes. Diabetic nephropathy significantly increases (P)RR level in kidneys, and use of (R)RR blocker, HRP, partially outcompeted renin and prorenin binding to (P)RR, normalized Ang II levels, or attenuated existing nephropathy $[75,76]$. In hypertensive animal models, HRP improved kidney and left ventricle function and decreased fibrosis. However, HRP failed to decrease blood pressure or renal injury in more complicated animal models, particularly in animal models with overexpressed prorenin and angiotensinogen [77]. In VSMC overexpressing human (P)RR, HRP failed to block prorenin binding to $(\mathrm{P}) \mathrm{RR}$ or ERK1/2 activation, whereas in human umbilical vein endothelial cells, HRP failed to bind to (P)RR [77, 78]. It is suggested that in patients with hemodialysis and increased cardiovascular death, inhibition of (P)RR in addition to ACEI or ARB might have the potential to positively reduce heart hypertrophy or protein excretion at least based on animal studies; however, HRP reversed the effects of DRI on blood pressure or coronary circulation [79]. Based on information presented above and complexity of RAS signaling or RAS inhibition negative feedback loop, HRP clinical use must first thoroughly understood in vitro and in vivo studies before clinical studies ensue.

4.3. Angiotensin Converting Enzyme Inhibitors (ACEIs). The use of ACEIs is an effective conventional treatment of hypertension and reducing left ventricular hypertrophy, therefore, ACEIs improve CV outcomes [80] ACEIs treatment of patients with a dysfunctional endothelium caused by various pathological conditions improves endothelial functions measured by brachial flow mediated vasodilation (FMD) [81]. Mechanistically, ACEIs improve endothelium function by increasing NO level via blocking bradykinin degradation and inhibit the production of endothelin-1 (ET-1) and Ang II by endothelium [82]. Maintaining bradykinin level has an additive effect on endothelium by increasing the level of prostacyclin and EDHF, both of which induce vasodilation and inhibit vascular smooth muscle cells proliferation and platelet adhesion [82-84]. Most recent evidence suggests that oxidative stress, inflammation, and hypertension are interrelated processes that influence each other in the pathology of hypertension-related cardiovascular events. Therefore, new inhibitors are being developed to target ACE and particularly to have antioxidant activity; so in concert the new properties of one inhibitor may contribute to endotheliumdependent protective effects against oxidative stress and high blood pressure. Several selenium analogues of ACE inhibitor, captopril, have been developed and shown to have ACE inhibitory effect and to scavenge oxidative stress product, peroxynitrite $[85,86]$. Although these new ACE inhibitors show promising inhibitory effects, extended in vitro and in vivo studies are necessary to understand and determine their extended physiological effect.

4.4. Ang 1-7 and Mas Axis. In addition to Ang II, other Ang peptides Ang III (Ang-2-8), Ang IV (Ang 3-8), and Ang
1-7 have biological effect within RAAS system [87]. Tissue and circulating Ang 1-7 level is similar to that of Ang II; however, unlike Ang II, Ang 1-7 is a vasodilator and mediates antiangiogenic and antimitogenic effects [87]. Ang 1-7 inhibits smooth muscles proliferation and inhibits neointima formation following carotid injury or abdominal aorta stenting [88, 89]. Ang 1-7 beneficial cardiovascular effects are mediated via $G$ protein-coupled receptor Mas (MasR). MasR have been shown to be present in human endothelial cells, afferent arterioles, collecting ducts of kidney, and glomerular mesangial cells [90]. The effect of Ang 1-7 on vascular beds is due to local synthesis of Ang 1-7 especially by endothelium, which mediates an array of vasodilators including EDHF and NO. However, in a patient study with heart failure treated with ACE inhibitor, local infusion of Ang 1-7 failed to induce a local vasodilation [91]. Indeed, losartan effects on decreasing blood pressure are thought to be mediated, partly, via Ang 1-7, since plasma level of Ang 1-7 was found to be increased during ACEI or ARB treatment [13]. The regulation of ACE2 and MasR, at least in hypertensive heart and kidney, was shown to be insensitive to Ang II or aldosterone signaling [92]. These data suggest RAAS-independent ACE2 and MasR regulation. Nevertheless, ACE2/Ang 1-7/MasR signaling has the potential to be considered a novel therapeutic approach to counterbalance ACE/Ang II/AT1R axis as a novel approach targeting RAAS [87].

4.5. Angiotensin Receptors Blockers (ARBs). Blockade of RAAS with ARBs has been shown to reduce inflammation and to improve endothelial function. In vitro and in vivo studies demonstrate that anti-inflammatory effect of ARB candesartan is through the suppression of the inflammatory toll-like receptors 2 and 4 (TLR2 and TLR4) [17]. Indeed, TLRs have been implicated in development and progression of cardiovascular disease. In animal models of hypertension, TLR4 contributes to blood pressure regulation and small resistance arteries vasoconstriction [93]. In hypertensive patients, ARB irbesartan has been shown to improve endothelial function and vascular reactivity and to reduce the levels of CRP, ICAM-1, IL-6, and oxidative stress marker 8isoprostane [94]. It is well known that oxidative stress plays an important role in mediating endothelium dysfunction. Use of valsartan has been shown to prevent the formation of reactive oxygen species (ROS) and to suppress the activity of $\mathrm{NF}-\kappa \mathrm{B}$, a transcription factor that regulates the expression of inflammatory cytokines and cell adhesion molecules, all of which contribute to development of vascular inflammation and of vascular events [95]. In vitro and in vivo studies have shown that ARB olmesartan inhibits Ang II-induced aortic vascular smooth muscle cells migration and therefore prevents vascular remodeling [96]. Use of ARBs, in patients with type 2 diabetes mellitus or with stable coronary artery disease, increases the number of cardioprotective and endothelial progenitor cells [97, 98]. ARBs exert beneficial effects for the treatment of coronary disease and atherosclerosis. Losartan treatment improves flow-mediated coronary artery disease in patients with atherosclerosis and endothelial function via NO bioavailability. 
4.6. Mineralocorticoid Receptor Antagonists (MRA). Dysregulated mineralocorticoid system signaling influences hypertension, atherosclerosis, and cardiac failure independent of renal MR actions on blood pressure [99]. Aberrantly activated MR negatively modulates endothelium function in patients with cardiovascular risk factors and disease. Blocking aldosterone effects at the level of MR with the currently available antagonists, eplerenone and spironolactone, have been shown to be effective treatment options for hypertension and heart failure [100]. The effect of aldosterone on cardiovascular system is mediated via MR present in vascular smooth muscle cells, endothelial cells, and cardiomyocytes [101]. Studies have shown that activation of MR induces a plethora of signaling events in cardiovascular system including oxidative stress [102], inhibits vascular relaxation, and induces vascular inflammation, fibrosis, and remodeling [62]. Aldosterone-activated MR in human endothelial cells (EC) induces the expression of inflammatory factor ICAM-1 and leukocytes-EC adhesion, and blocking MR with spironolactone inhibits aldosterone-mediated effects on EC [102]. Aldosterone impairs EPC differentiation, migration, and proliferation, whereas pharmacological inhibition or genetic manipulation of aldosterone rescues EPC functions $[103,104]$. Inhibition of MR with spironolactone improves endothelium-dependent vasodilatation via inhibition of NAD(P)H oxidase pathway [104]. Moreover, blocking aldosterone signaling improves heart muscles proliferation and arterial wall remodeling, endothelial function, and NO synthesis [60]. Many clinical studies have shown that pharmacological inhibition of MR decreases the incidence of heart attack, stroke, and mortality in addition to lowering blood pressure [101]. Most recent studies also show that additional benefits from blockade of aldosterone signaling particularly decreased inflammation, reduced cardiovascular remodeling, and reduced atherosclerosis [60]. However, use of MRA has been shown to indeed induce a countereffect such as an increase in aldosterone level, therefore potentiating MRindependent effects of aldosterone, particularly nongenomic effects such as stimulating contractility of CV system [105].

4.6.1. Development of New Mineralocorticoid Receptor Antagonists. Current research is underway to develop new MRA due to limited number of clinically approved MRA, spironolactone and eplerenone in USA and canrenone in Europe. MR structure-based drug design studies have identified several compounds; however, only a limited number of new MRA candidates have been advanced to clinical studies. One such new MRA, PF-3882845, significantly attenuated blood pressure, reduced urinary albumin, and protected kidney in Dahl-salt induced hypertension animal model. These results advanced this new MRA to ongoing clinical studies [106]. More recent MR antagonists such as dihydrofuran1-one and dihydropyrrol-2-one show very promising $\mathrm{MR}$ binding selectivity in in vitro studies [107]. However, other recent selective nonsteroidal molecule, BR-4628, has been developed and displays high potency and selectivity for MR in both, in vivo and in vitro, studies [108]. In DOCA-salt hypertensive rats, BR-4628 treatment significantly decreased serum inflammation marker MCP-1, IL-1beta, CXCL-1, and kidney damage markers MCP-1, tenascin-1, and osteopontin. Moreover, BR-4628 treatment decreased DOCA-salt induced oxidative stress and DNA damage. However, BR-4628 treatment produced a modest decrease in systolic blood pressure in DOCA-salt group, whereas spironolactone significantly decreased systolic blood pressure compared to DOCA-salt group. These findings suggest tissue activation of MR and BR4628 antagonism in tissue, rather than systemic effect such as decreasing blood pressure [109]. More studies are necessary to determine BR-4628 efficacy in reducing blood pressure.

4.7. Aldosterone Synthase Inhibitors. Decreasing aldosterone synthesis at its enzyme step, aldosterone synthase (AS), CYP11B2, is the novel alternative approach to MRA to limit aldosterone effects [105]. Aldosterone synthase inhibitors (ASI) represent the latest therapeutic strategy to decrease aldosterone production [110]. Fadrozole 286A (FAD 286A) has been shown to dose-dependently inhibit Ang II-induced aldosterone synthesis in human adrenocortical carcinoma cells, whereas in animal models it decreased plasma renin activity, cardiac hypertrophy, and cardiac remodeling [111113]. Based on FAD 286A, a new AS inhibitor, LCI699, has been developed and is the first generation ASI that has been tested in clinical trials. In clinical trials, administration of LCI699 has been shown to reduce plasma and urine aldosterone level in participants with sodium-depleted levels, to lower blood pressure in patients with essential hypertension and to balance hypokalemia in patients with aldosteronism [110, 114, 115]. Moreover, LCI699 has been recently shown to modestly reduce blood pressure (BP) in patients with resistant hypertension [116]. However, in a study by Karns et al. [116], pharmacological effect of LCI699 was tested on primary aldosteronism, resistant and uncontrolled hypertension, and essential hypertension [106]. In this study, the first generation of ASI, LCI699, has been found to exhibit some limitations, that is, to interfere with major endocrine feedback loops: the RAAS and hypothalamicpituitary-adrenal (HPA). LCI699 potentiated a higher than accepted physiological level of 11-deoxycorticosterone and adrenocorticotropic hormone (ACTH). The increased levels of 11-deoxycorticosterone and ACTH are components of two different endocrine feedback loops which indeed converge at one point: a potent mineralocorticoid receptor, data which supports a modest LCI699 effect on lowering blood pressure. This data also suggests the need for more in vivo studies to fully understand the physiological effect of LCI699.

\section{RAAS and Vascular Remodeling}

Ang II also induces vascular remodeling, thrombosis, and plaques rupture $[117,118]$. Ang II mediated vascular remodeling is via the expression of autocrine growth factors basic fibroblast growth factor (bFBS), transforming growth factor- $\beta 1$ (TGF $\beta 1$ ), and insulin growth factor (IGF) [119]. Vascular remodeling mediated by Ang II is due to increased vascular cell migration and modification of extracellular matrix composition $[96,120]$. Changes in the structure 
and function of blood vessels especially in small resistance blood vessels potentiate the complications of hypertension. Moreover, remodeling of small blood vessels occurs before left ventricular hypertrophy and carotid artery intima-media thickening or increases microalbuminuria levels. Indeed, a smaller lumen and external diameter of small resistance arteries is seen in patients with hypertension [121]. Changes in the function of small arteries are associated with decreased levels of vasodilators and increased sensitivity to Ang II and related signal transduction pathways.

In addition to its role in hypertension, the renin-angiotensin-aldosterone system also plays an important role in mediating vascular remodeling in neointimal hyperplasia after angioplasty and atherosclerosis [122-124]. Ang II is also a growth factor that regulates cell proliferation and differentiation, hypertrophy, and apoptosis. In vascular remodeling, Ang II-induced remodeling effects are due to vascular smooth muscle cells proliferation and hypertrophy. The Ang II growth effects, proliferation versus hypertrophy, are dependent on cell type and cell-cycle regulated genes. For example, Ang II exerts hypertrophic effect on cardiomyocytes via TGF $\beta 1$ mediated signaling, and blockade of TGF $\beta 1$ receptor abrogates Ang II-mediated cardiomyocytes hypertrophy [125]. In myocardial infarction model (MI), ARB, telmisartan, inhibits cardiac remodeling by reducing cardiomyocytes hypertrophy and fibrosis via an anti-inflammatory effect and activation of peroxisome proliferators-activated receptor gamma (PPAR $\gamma)$ [126]. The role of systemic and local reninangiotensin system in vascular remodeling diseases such as atherosclerosis and neointima hyperplasia after angioplasty is well established [127]. Ang II/AT1R activation within vascular tissue leads to accumulation of inflammatory cells, fibrosis, and migration of vascular smooth muscle cells [128]. Blocking of Ang II signaling via ACEIs or ARBs has been shown to inhibit Ang II-mediated endothelial dysfunction and atherosclerosis [129], and ARBs efficiently inhibited vascular remodeling and neointimal hyperplasia after vascular injury $[130,131]$. Indeed, ARB telmisartan has been shown to suppress neointima hyperplasia after heart transplant in a mouse model, suggesting that telmisartan might provide positive effects in preventing graft rejection [132]. ARB losartan has been shown to decrease intima : media ratio of carotid artery or in resistance arteries in hypertensive patients and to prevent the production of TGF $\beta$, a known mediator of Ang II $[133,134]$. Aldosterone plays a key role in cardiac fibrosis and remodeling via direct effects on collagen synthesis and deposition in the cardiac interstitium. Use of spironolactone in rat model of myocardial fibrosis prevents myocardial fibrosis [135]. Therefore, there is increasing evidence indicating that pharmacologically blocking RAAS signaling positively regulates vascular inflammation and remodeling and cardiovascular physiology (for summary of above results, see Table 1).

\section{Perspective on RAAS Inhibition}

Although RAAS system has been studied for more than a century, new experimental and clinical evidences suggest that the physiology of RAAS is complex and multifactorial, and new or on-going research will provide a better understanding on RAAS physiology. For example, the current understanding about interactions between Ang II and aldosterone to regulate deleterious cellular processes indicates the intricacy of RAAS signaling and provides the basis for blocking RAAS at multiple levels. Although new RAAS targets and inhibitors are being developed, more studies are needed to identify the molecular mechanisms and physiological interactions. Moreover, identifying novel targets/effectors of the RAAS system perhaps will provide the basis for the development of novel therapeutic strategies aimed at preventing vascular inflammation and remodeling and therefore improving the outcome of cardiovascular disease.

\author{
Abbreviations \\ AS: $\quad$ Aldosterone synthase \\ ASI: Aldosterone synthase inhibitors \\ Ang: Angiotensin \\ ACE: Angiotensin converting enzyme \\ ARB: Angiotensin receptor blockers \\ CRP: C-reactive protein \\ CVD: Cardiovascular disease \\ DRI: Direct rennin inhibitors \\ EPC: $\quad$ Endothelial progenitor cells \\ ERK: Extracellular receptor kinase \\ EGFR: Epidermal growth factor receptor \\ eNOS: Endothelial nitric oxide synthase \\ EDHF: Endothelium-derived hyperpolarizing \\ factor \\ ET-1: Endothelin 1 \\ IL-1 $\beta$ : Interleukin 1 beta \\ IL-6: Interleukin 6 \\ ICAM-1: Intracellular cell adhesion molecule 1 \\ IGF: Insulin growth factor \\ MCP-1: Monocytes chemoattractant protein 1 \\ MIP-1: $\quad$ Macrophages inflammatory protein 1 \\ MRA: Mineralocorticoid receptor antagonist \\ NF- $\kappa$ B: Nuclear factor kappa B \\ NO: $\quad$ Nitric oxide \\ PPAR $\gamma$ : Peroxisome proliferators-activated \\ receptor gamma \\ RAAS: Renin-angiotensin-aldosterone system \\ TGF $\beta$ : Transforming growth factor beta \\ TNF $\alpha$ : Tumor necrosis factor alpha \\ VCAM-1: Vascular cell adhesion molecule 1.
}

\section{Conflict of Interests}

The authors declare that there is no conflict of interests regarding the publication of this paper.

\section{Acknowledgment}

This research was financially supported by a grant from National Institutes of Health (Grant no. G12MD007581) 
through the RCMI-Center for Environmental Health at Jackson State University.

\section{References}

[1] C. M. Ferrario and W. B. Strawn, "Role of the renin-angiotensinaldosterone system and proinflammatory mediators in cardiovascular disease," American Journal of Cardiology, vol. 98, no. 1, pp. 121-128, 2006.

[2] H. Goldblatt, J. Lynch, R. F. Hanzal, and W. W. Summerville, "Studies on experimental hypertension: I. The production of persistent elevation of systolic blood pressure by means of renal ischemia," The Journal of Experimental Medicine, vol. 59, no. 3, pp. 347-379, 1934.

[3] F. Fyhrquist and O. Saijonmaa, "Renin-angiotensin system revisited," Journal of Internal Medicine, vol. 264, no. 3, pp. 224236, 2008.

[4] E. Pimenta and S. Oparil, "Role of aliskiren in cardio-renal protection and use in hypertensives with multiple risk factors," Therapeutics and Clinical Risk Management, vol. 5, no. 1, pp. 453-463, 2009.

[5] G. Nguyen, F. Delarue, C. Burcklé, L. Bouzhir, T. Giller, and J.-D. Sraer, "Pivotal role of the renin/prorenin receptor in angiotensin II production and cellular responses to renin," The Journal of Clinical Investigation, vol. 109, no. 11, pp. 1417-1427, 2002.

[6] Y. Huang, N. A. Noble, J. Zhang, C. Xu, and W. A. Border, "Renin-stimulated TGF- $\beta 1$ expression is regulated by a mitogen-activated protein kinase in mesangial cells," Kidney International, vol. 72, no. 1, pp. 45-52, 2007.

[7] J. A. Staessen, Y. Li, and T. Richart, "Oral renin inhibitors," The Lancet, vol. 368, no. 9545, pp. 1449-1456, 2006.

[8] M. J. Brown, “Aliskiren," Circulation, vol. 118, no. 7, pp. 773-784, 2008.

[9] S. J. Quinn and G. H. Williams, "Regulation of aldosterone secretion," Annual Review of Physiology, vol. 50, pp. 409-426, 1988.

[10] F. Gustafsson, M. Azizi, J. Bauersachs, F. Jaisser, and P. Rossignol, "Targeting the aldosterone pathway in cardiovascular disease," Fundamental and Clinical Pharmacology, vol. 26, no. 1, pp. 135-145, 2012.

[11] M. Donoghue, F. Hsieh, E. Baronas et al., "A novel angiotensinconverting enzyme-related carboxypeptidase (ACE2) converts angiotensin I to angiotensin 1-9," Circulation Research, vol. 87, no. 5, pp. E1-E9, 2000.

[12] J. Zhong, D. Guo, C. B. Chen et al., "Prevention of angiotensin II-mediated renal oxidative stress, inflammation, and fibrosis by angiotensin-converting enzyme 2," Hypertension, vol. 57, no. 2, pp. 314-322, 2011.

[13] C. M. Ferrario, "Angiotensin-converting enzyme 2 and angiotensin-(1-7): an evolving story in cardiovascular regulation," Hypertension, vol. 47, no. 3, pp. 515-521, 2006.

[14] V. Richard, S. Hurel-Merle, E. Scalbert et al., "Functional evidence for a role of vascular chymase in the production of angiotensin II in isolated human arteries," Circulation, vol. 104, no. 7, pp. 750-752, 2001.

[15] H. Urata, F. Strobel, and D. Ganten, "Widespread tissue distribution of human chymase," Journal of Hypertension, Supplement, vol. 12, no. 9, pp. S17-S22, 1994.

[16] R. P. Tracy, "Inflammation in cardiovascular disease: cart, horse, or both?" Circulation, vol. 97, no. 20, pp. 2000-2002, 1998.
[17] R. P. Mason, "Optimal therapeutic strategy for treating patients with hypertension and atherosclerosis: focus on olmesartan medoxomil," Vascular Health and Risk Management, vol. 7, pp. 405-416, 2011.

[18] N. Parameswaran and S. Patial, "Tumor necrosis factor-a signaling in macrophages," Critical Reviews in Eukaryotic Gene Expression, vol. 20, no. 2, pp. 87-103, 2010.

[19] X. Gao, S. Belmadani, A. Picchi et al., "Tumor necrosis factor- $\alpha$ induces endothelial dysfunction in Lepr db mice," Circulation, vol. 115, no. 2, pp. 245-254, 2007.

[20] J. Pelisek, M. Rudelius, P. Zepper et al., "Multiple biological predictors for vulnerable carotid lesions," Cerebrovascular Diseases, vol. 28, no. 6, pp. 601-610, 2009.

[21] G. Russo, J. A. Leopold, and J. Loscalzo, "Vasoactive substances: nitric oxide and endothelial dysfunction in atherosclerosis," Vascular Pharmacology, vol. 38, no. 5, pp. 259-269, 2002.

[22] M. A. Zimmerman, C. H. Selzman, L. L. Reznikov et al., "Lack of TNF- $\alpha$ attenuates intimal hyperplasia after mouse carotid artery injury," American Journal of Physiology-Regulatory Integrative and Comparative Physiology, vol. 283, no. 2, pp. R505$\mathrm{R} 512,2002$.

[23] M. Fujita, J. M. Shannon, C. G. Irvin et al., "Overexpression of tumor necrosis factor- $\alpha$ produces an increase in lung volumes and pulmonary hypertension," American Journal of Physiology_Lung Cellular and Molecular Physiology, vol. 280, no. 1, pp. L39-L49, 2001.

[24] C. M. Lambert, M. Roy, J. Meloche et al., "Tumor necrosis factor inhibitors as novel therapeutic tools for vascular remodeling diseases," American Journal of Physiology-Heart and Circulatory Physiology, vol. 299, no. 4, pp. H995-H1001, 2010.

[25] K. Krasinski, I. Spyridopoulos, M. Kearney, and D. W. Losordo, "In vivo blockade of tumor necrosis factor- $\alpha$ accelerates functional endothelial recovery after balloon angioplasty," Circulation, vol. 104, no. 15, pp. 1754-1756, 2001.

[26] Y. Han, M. S. Runge, and A. R. Brasier, "Angiotensin II induces interleukin-6 transcription in vascular smooth muscle cells through pleiotropic activation of nuclear factor- $\kappa \mathrm{b}$ transcription factors," Circulation Research, vol. 84, no. 6, pp. 695-703, 1999.

[27] D. B. Landry, L. L. Couper, S. R. Bryant, and V. Lindner, "Activation of the NF- $\kappa$ B and I $\kappa$ B system in smooth muscle cells after rat arterial injury: induction of vascular cell adhesion molecule1 and monocyte chemoattractant protein-1," American Journal of Pathology, vol. 151, no. 4, pp. 1085-1095, 1997.

[28] R. von Känel, P. J. Mills, B. T. Mausbach et al., "Effect of Alzheimer caregiving on circulating levels of $\mathrm{C}$-reactive protein and other biomarkers relevant to cardiovascular disease risk: a longitudinal study," Gerontology, vol. 58, pp. 354-365, 2012.

[29] J. Hurlimann, G. J. Thorbecke, and G. M. Hochwald, "The liver as the site of C-reactive protein formation," Journal of Experimental Medicine, vol. 123, no. 2, pp. 365-378, 1966.

[30] P. Calabró, J. T. Willerson, and E. T. H. Yeh, "Inflammatory cytokines stimulated C-reactive protein production by human coronary artery smooth muscle cells," Circulation, vol. 108, no. 16, pp. 1930-1932, 2003.

[31] V. Pasceri, J. T. Willerson, and E. T. H. Yeh, "Direct proinflammatory effect of C-reactive protein on human endothelial cells," Circulation, vol. 102, no. 18, pp. 2165-2168, 2000.

[32] S. Verma, M. A. Kuliszewski, S.-H. Li et al., "C-reactive protein attenuates endothelial progenitor cell survival, differentiation, and function: further evidence of a mechanistic link between 
C-reactive protein and cardiovascular disease," Circulation, vol. 109, no. 17, pp. 2058-2067, 2004.

[33] C.-H. Wang, S.-H. Li, R. D. Weisel et al., "C-reactive protein upregulates angiotensin type 1 receptors in vascular smooth muscle," Circulation, vol. 107, no. 13, pp. 1783-1790, 2003.

[34] F. G. Hage, S. Oparil, D. Xing, Y.-F. Chen, M. A. McCrory, and A. J. Szalai, "C-reactive protein-mediated vascular injury requires complement," Arteriosclerosis, Thrombosis, and Vascular Biology, vol. 30, no. 6, pp. 1189-1195, 2010.

[35] P. Libby and P. Theroux, "Pathophysiology of coronary artery disease," Circulation, vol. 111, no. 25, pp. 3481-3488, 2005.

[36] J. Danesh, J. Muir, Y.-K. Wong, M. Ward, J. R. Gallimore, and M. B. Pepys, "Risk factors for coronary heart disease and acutephase proteins. A population-based study," European Heart Journal, vol. 20, no. 13, pp. 954-959, 1999.

[37] W.-B. Tang, Y.-Q. Zhou, T. Zhao et al., "Effect of interleukin-6 (IL-6) on the vascular smooth muscle contraction in abdominal aorta of rats with streptozotocin-induced diabetes," Chinese Journal of Physiology, vol. 54, no. 5, pp. 318-323, 2011.

[38] M. K. Steiner, O. L. Syrkina, N. Kolliputi, E. J. Mark, C. A. Hales, and A. B. Waxman, "Interleukin-6 overexpression induces pulmonary hypertension," Circulation Research, vol. 104, no. 2, pp. 236-244, 2009.

[39] P. O. Iversen, A. Nicolaysen, K. Kvernebo, H. B. Benestad, and G. Nicolaysen, "Human cytokines modulate arterial vascular tone via endothelial receptors," Pflugers Archiv, vol. 439, no. 1-2, pp. 93-100, 1999.

[40] J.-P. Empana, X. Jouven, F. Canouï-Poitrine et al., "C-reactive protein, interleukin 6, fibrinogen and risk of sudden death in European middle-aged men: the PRIME study," Arteriosclerosis, Thrombosis, and Vascular Biology, vol. 30, no. 10, pp. 2047-2052, 2010.

[41] T. Niida, K. Isoda, M. Kitagaki et al., "I $\kappa$ BNS regulates interleukin-6 production and inhibits neointimal formation after vascular injury in mice," Cardiovascular Research, vol. 93, no. 2, pp. 371-379, 2012.

[42] L. E. Rohde, R. T. Lee, J. Rivero et al., "Circulating cell adhesion molecules are correlated with ultrasound- based assessment of carotid atherosclerosis," Arteriosclerosis, Thrombosis, and Vascular Biology, vol. 18, no. 11, pp. 1765-1770, 1998.

[43] M. F. Neves, F. Amiri, A. Virdis, Q. N. Diep, and E. L. Schiffrin, "Role of aldosterone in angiotensin II-induced cardiac and aortic inflammation, fibrosis, and hypertrophy," Canadian Journal of Physiology and Pharmacology, vol. 83, no. 11, pp. 999-1006, 2005.

[44] M. E. Pueyo, W. Gonzalez, A. Nicoletti, F. Savoie, J.-F. Arnal, and J.-B. Michel, "Angiotensin II stimulates endothelial vascular cell adhesion molecule- 1 via nuclear factor- $\kappa \mathrm{B}$ activation induced by intracellular oxidative stress," Arteriosclerosis, Thrombosis, and Vascular Biology, vol. 20, no. 3, pp. 645-651, 2000.

[45] S. Masiha, J. Sundström, and L. Lind, "Inflammatory markers are associated with left ventricular hypertrophy and diastolic dysfunction in a population-based sample of elderly men and women," Journal of Human Hypertension, vol. 27, pp. 13-17, 2013.

[46] Á. Álvarez, M. Cerdá-Nicolás, Y. Naim Abu Nabah et al., "Direct evidence of leukocyte adhesion in arterioles by angiotensin II," Blood, vol. 104, no. 2, pp. 402-408, 2004.

[47] R. Kranzhöfer, J. Schmidt, C. A. Pfeiffer, S. Hagl, P. Libby, and W. Kübler, "Angiotensin induces inflammatory activation of human vascular smooth muscle cells," Arteriosclerosis, Thrombosis, and Vascular Biology, vol. 19, no. 7, pp. 1623-1629, 1999.
[48] A. W. Hahn, U. Jonas, F. R. Bühler, and T. J. Resink, "Activation of human peripheral monocytes by angiotensin II," FEBS Letters, vol. 347, no. 2-3, pp. 178-180, 1994.

[49] P. E. Tummala, X.-L. Chen, C. L. Sundell et al., "Angiotensin II induces vascular cell adhesion molecule-1 expression in rat vasculature: a potential link between the renin-angiotensin system and atherosclerosis," Circulation, vol. 100, no. 11, pp. 1223-1229, 1999.

[50] X.-L. Chen, P. E. Tummala, M. T. Olbrych, R. W. Alexander, and R. M. Medford, "Angiotensin II induces monocyte chemoattractant protein-1 gene expression in rat vascular smooth muscle cells," Circulation Research, vol. 83, no. 9, pp. 952-959, 1998.

[51] U. M. Becher, C. Endtmann, V. Tiyerili, G. Nickenig, and N. Werner, "Endothelial damage and regeneration: the role of the renin-angiotensin- aldosterone system," Current Hypertension Reports, vol. 13, no. 1, pp. 86-92, 2011.

[52] S. Rajagopalan, S. Kurz, T. Münzel et al., "Angiotensin IImediated hypertension in the rat increases vascular superoxide production via membrane NADH/NADPH oxidase activation: contribution to alterations of vasomotor tone," The Journal of Clinical Investigation, vol. 97, no. 8, pp. 1916-1923, 1996.

[53] S. Wassmann and G. Nickenig, "Pathophysiological regulation of the AT1-receptor and implications for vascular disease," Journal of Hypertension, vol. 24, no. 1, pp. S15-S21, 2006.

[54] G. Qi, L. Jia, Y. Li et al., "Angiotensin II infusion-induced inflammation, monocytic fibroblast precursor infiltration, and cardiac fibrosis are pressure dependent," Cardiovascular Toxicology, vol. 11, no. 2, pp. 157-167, 2011.

[55] R. Gul, A. I. Shawl, S.-H. Kim, and U.-H. Kim, "Cooperative interaction between reactive oxygen species and $\mathrm{Ca}^{2+}$ signals contributes to angiotensin II-induced hypertrophy in adult rat cardiomyocytes," American Journal of Physiology-Heart and Circulatory Physiology, vol. 302, no. 4, pp. H901-H909, 2012.

[56] A. A. Geisterfer, M. J. Peach, and G. K. Owens, "Angiotensin II induces hypertrophy, not hyperplasia, of cultured rat aortic smooth muscle cells," Circulation Research, vol. 62, no. 4, pp. 749-756, 1988.

[57] C. P. Judkins, H. Diep, B. R. S. Broughton et al., "Direct evidence of a role for Nox 2 in superoxide production, reduced nitric oxide bioavailability, and early atherosclerotic plaque formation in ApoE $^{-/-}$mice," American Journal of Physiology-Heart and Circulatory Physiology, vol. 298, no. 1, pp. H24-H32, 2010.

[58] Z. Li, M. Iwai, L. Wu et al., "Fluvastatin enhances the inhibitory effects of a selective AT1 receptor blocker, valsartan, on atherosclerosis," Hypertension, vol. 44, no. 5, pp. 758-763, 2004.

[59] U. Förstermann and T. Münzel, "Endothelial nitric oxide synthase in vascular disease: from marvel to menace," Circulation, vol. 113, no. 13, pp. 1708-1714, 2006.

[60] F. A. Martinez, "Aldosterone inhibition and cardiovascular protection: more important than it once appeared," Cardiovascular Drugs and Therapy, vol. 24, no. 4, pp. 345-350, 2010.

[61] T. Cascella, Y. Radhakrishnan, L. A. Maile et al., "Aldosterone enhances IGF-I-mediated signaling and biological function in vascular smooth muscle cells," Endocrinology, vol. 151, no. 12, pp. 5851-5864, 2010.

[62] S. J. Sherajee, Y. Fujita, K. Rafiq et al., "Aldosterone induces vascular insulin resistance by increasing insulin-like growth factor1 receptor and hybrid receptor," Arteriosclerosis, Thrombosis, and Vascular Biology, vol. 32, no. 2, pp. 257-263, 2012.

[63] T. Marumo, H. Uchimura, M. Hayashi, K. Hishikawa, and T. Fujita, "Aldosterone impairs bone marrow-derived progenitor cell formation," Hypertension, vol. 48, no. 3, pp. 490-496, 2006. 
[64] J. P. Cooke, A. H. Singer, P. Tsao, P. Zera, R. A. Rowan, and M. E. Billingham, "Antiatherogenic effects of L-arginine in the hypercholesterolemic rabbit," The Journal of Clinical Investigation, vol. 90, no. 3, pp. 1168-1172, 1992.

[65] J. L. Cook, Z. Zhang, and R. N. Re, "In vitro evidence for an intracellular site of angiotensin action," Circulation Research, vol. 89, no. 12, pp. 1138-1146, 2001.

[66] M. K. Hunt, S. P. Ramos, K. M. Geary et al., "Colocalization and release of angiotensin and renin in renal cortical cells," American Journal of Physiology-Renal Fluid and Electrolyte Physiology, vol. 263, no. 3, pp. F363-F373, 1992.

[67] J. M. Wang, D. Slembrouck, J. Tan et al., "Presence of cellular renin-angiotensin system in chromaffin cells of bovine adrenal medulla," American Journal of Physiology-Heart and Circulatory Physiology, vol. 283, no. 5, pp. H1811-H1818, 2002.

[68] S. B. Rajamohan, G. Raghuraman, N. R. Prabhakar, and G. K. Kumar, "Nadph oxidase-derived $\mathrm{H}_{2} \mathrm{O}_{2}$ contributes to angiotensin ii-induced aldosterone synthesis in human and rat adrenal cortical cells," Antioxidants \& Redox Signaling, vol. 17, no. 3, pp. 445-459, 2012.

[69] S. J. Mansur, F. G. Hage, and S. Oparil, "Have the reninangiotensin-aldosterone system perturbations in cardiovascular disease been exhausted?" Current Cardiology Reports, vol. 12, no. 6, pp. 450-463, 2010.

[70] K. Andersen, M. H. Weinberger, C. M. Constance et al., "Comparative effects of aliskiren-based and ramipril-based therapy on the renin system during long-term (6 months) treatment and withdrawal in patients with hypertension," Journal of the ReninAngiotensin-Aldosterone System, vol. 10, no. 3, pp. 157-167, 2009.

[71] T. Gossas, L. Vrang, I. Henderson et al., "Aliskiren displays longlasting interactions with human renin," Naunyn-Schmiedeberg's Archives of Pharmacology, vol. 385, no. 2, pp. 219-224, 2012.

[72] J. Yamauchi, Y. Shibagaki, K. Uehara, T. Yasuda, and K. Kimura, "Aliskiren-associated acute kidney injury in a patient with preexisting chronic kidney disease and dilated cardiomyopathy," Clinical and Experimental Nephrology, vol. 16, pp. 333-336, 2012.

[73] S. Kühnast, J. W. A. van der Hoorn, A. M. van den Hoek et al., "Aliskiren inhibits atherosclerosis development and improves plaque stability in APOE* 3Leiden.CETP transgenic mice with or without treatment with atorvastatin," Journal of Hypertension, vol. 30, no. 1, pp. 107-116, 2012.

[74] G. Liu, H. Hitomi, N. Hosomi et al., "Prorenin induces vascular smooth muscle cell proliferation and hypertrophy via epidermal growth factor receptor-mediated extracellular signal-regulated kinase and Akt activation pathway," Journal of Hypertension, vol. 29, no. 4, pp. 696-705, 2011.

[75] K. Takahashi, H. Yamamoto, T. Hirose et al., "Expression of (pro)renin receptor in human kidneys with end-stage kidney disease due to diabetic nephropathy," Peptides, vol. 31, no. 7, pp. 1405-1408, 2010.

[76] L. C. Matavelli, J. Huang, and H. M. Siragy, "(Pro)renin receptor contributes to diabetic nephropathy by enhancing renal inflammation," Clinical and Experimental Pharmacology and Physiology, vol. 37, no. 3, pp. 277-282, 2010.

[77] S. Feldt, U. Maschke, R. Dechend, F. C. Luft, and D. N. Muller, "The putative (pro)renin receptor blocker HRP fails to prevent (pro)renin signaling," Journal of the American Society of Nephrology, vol. 19, no. 4, pp. 743-748, 2008.

[78] B. J. Leckie and A. R. Bottrill, "A specific binding site for the prorenin propart peptide Arg10-Arg20 does not occur on human endothelial cells," Journal of the Renin-AngiotensinAldosterone System, vol. 12, no. 1, pp. 36-41, 2011.
[79] J. H. M. van Esch, R. van Veghel, I. M. Garrelds, F. Leijten, A. M. Bouhuizen, and A. H. J. Danser, "Handle region peptide counteracts the beneficial effects of the renin inhibitor aliskiren in spontaneously hypertensive rats," Hypertension, vol. 57, no. 4, pp. 852-858, 2011.

[80] R. E. Schmieder, P. Martus, and A. Klingbeil, "Reversal of left ventricular hypertrophy in essential hypertension: a metaanalysis of randomized double-blind studies," Journal of the American Medical Association, vol. 275, no. 19, pp. 1507-1513, 1996.

[81] Y. Shahin, J. A. Khan, N. Samuel, and I. Chetter, "Angiotensin converting enzyme inhibitors effect on endothelial dysfunction: a meta-analysis of randomised controlled trials," Atherosclerosis, vol. 216, no. 1, pp. 7-16, 2011.

[82] H. Brunner, J. R. Cockcroft, J. Deanfield et al., "Endothelial function and dysfunction-part II: association with cardiovascular risk factors and diseases. A statement by the Working Group on Endothelins and Endothelial Factors of the European Society of Hypertension," Journal of Hypertension, vol. 23, no. 2, pp. 233-246, 2005.

[83] S. E. Barrow, C. T. Dollery, D. J. Heavey, N. E. Hickling, J. M. Ritter, and J. Vial, "Effect of vasoactive peptides on prostacyclin synthesis in man," British Journal of Pharmacology, vol. 87, no. 1, pp. 243-247, 1986.

[84] J.-V. Mombouli, S. Illiano, T. Nagao, T. Scott-Burden, and P. M. Vanhoutte, "Potentiation of endothelium-dependent relaxations to bradykinin by angiotensin I converting enzyme inhibitors in canine coronary artery involves both endotheliumderived relaxing and hyperpolarizing factors," Circulation Research, vol. 71, no. 1, pp. 137-144, 1992.

[85] B. J. Bhuyan and G. Mugesh, "Synthesis, characterization and antioxidant activity of angiotensin converting enzyme inhibitors," Organic and Biomolecular Chemistry, vol. 9, no. 5, pp. 1356-1365, 2011.

[86] B. J. Bhuyan and G. Mugesh, "Antioxidant activity of peptidebased angiotensin converting enzyme inhibitors," Organic and Biomolecular Chemistry, vol. 10, no. 11, pp. 2237-2247, 2012.

[87] R. A. S. Santos, A. C. Simoes e Silva, C. Maric et al., "Angiotensin-(1-7) is an endogenous ligand for the G proteincoupled receptor Mas," Proceedings of the National Academy of Sciences of the United States of America, vol. 100, no. 14, pp. 8258-8263, 2003.

[88] R. A. S. Santos, A. J. Ferreira, and A. C. Simoes e Silva, "Recent advances in the angiotensin-converting enzyme 2-angiotensin(1-7)-Mas axis," Experimental Physiology, vol. 93, no. 5, pp. 519-527, 2008.

[89] W. B. Strawn, S. M. Ferrario, and E. A. Tallant, "Angiotensin, (17) attenuates neointimal foramtion after stent implantation in the rat," Hypertension, vol. 45, pp. 138-141, 2005.

[90] R. A. Santos, A. J. Ferreira, T. Verano-Brage, and M. Bader, "Angiotensin-converting enzyme 2, angiotensin-(1-7) and Mas: new players of the renin-angiotensin system," The Journal of Endocrinology, vol. 216, no. 2, pp. R1-R17, 2013.

[91] A. P. Davie and J. J. V. McMurray, "Effect of angiotensin-(1-7) and bradykinin in patients with heart failure treated with an ACE inhibitor," Hypertension, vol. 34, no. 3, pp. 457-460, 1999.

[92] W. Meng, W. Zhao, T. Zhao et al., "Autocrine and paracrine function of angiotensin 1-7 in tissue repair during hypertension," American Journal of Hypertension, 2014. 
[93] G. F. Bomfim, R. A. dos Santos, M. A. Oliveira et al., "Toll-like receptor 4 contributes to blood pressure regulation and vascular contraction in spontaneously hypertensive rats," Clinical Science, vol. 122, no. 11, pp. 535-543, 2012.

[94] S. Sola, M. Q. S. Mir, F. A. Cheema et al., "Irbesartan and lipoic acid improve endothelial function and reduce markers of inflammation in the metabolic syndrome: results of the Irbesartan and Lipoic Acid in Endothelial Dysfunction (ISLAND) study," Circulation, vol. 111, no. 3, pp. 343-348, 2005.

[95] P. Dandona, V. Kumar, A. Aljada et al., "Angiotensin II receptor blocker valsartan suppresses reactive oxygen species generation in leukocytes, nuclear factor- $\kappa \mathrm{B}$, in mononuclear cells of normal subjects: evidence of an antiinflammatory action," Journal of Clinical Endocrinology and Metabolism, vol. 88, no. 9, pp. 44964501, 2003.

[96] Y. Kyotani, J. Zhao, S. Tomita et al., "Olmesartan inhibits angiotensin II-induced migration of vascular smooth muscle cells through src and mitogen-activated protein kinase pathways," Journal of Pharmacological Sciences, vol. 113, no. 2, pp. 161-168, 2010.

[97] T. Q. Min, C. J. Zhu, W. X. Xiang, Z. J. Hui, and S. Y. Peng, "Improvement in endothelial progenitor cells from peripheral blood by ramipril therapy in patients with stable coronary artery disease," Cardiovascular Drugs and Therapy, vol. 18, no. 3, pp. 203-209, 2004.

[98] F. H. Bahlmann, K. de Groot, O. Mueller, B. Hertel, H. Haller, and D. Fliser, "Stimulation of endothelial progenitor cells: a new putative therapeutic effect of angiotensin II receptor antagonists," Hypertension, vol. 45, no. 4, pp. 526-529, 2005.

[99] M. Caprio, C. Mammi, I. Z. Jaffe et al., “The mineralocorticoid receptor in endothelial physiology and disease: novel concepts in the understanding of erectile dysfunction," Current Pharmaceutical Design, vol. 14, no. 35, pp. 3749-3757, 2008.

[100] F. Zannad, J. J. V. McMurray, H. Krum et al., "Eplerenone in patients with systolic heart failure and mild symptoms," The New England Journal of Medicine, vol. 364, no. 1, pp. 11-21, 2011.

[101] A. McCurley and I. Z. Jaffe, "Mineralocorticoid receptors in vascular function and disease," Molecular and Cellular Endocrinology, vol. 350, no. 2, pp. 256-265, 2012.

[102] M. Caprio, B. G. Newfell, A. la Sala et al., "Functional mineralocorticoid receptors in human vascular endothelial cells regulate intercellular adhesion molecule-1 expression and promote leukocyte adhesion," Circulation Research, vol. 102, no. 11, pp. 1359-1367, 2008.

[103] T. Thum, K. Schmitter, F. Fleissner et al., "Impairment of endothelial progenitor cell function and vascularization capacity by aldosterone in mice and humans," European Heart Journal, vol. 32, no. 10, pp. 1275-1286, 2011.

[104] I. C. Haznedaroglu and M. A. Öztürk, "Towards the understanding of the local hematopoietic bone marrow reninangiotensin system," International Journal of Biochemistry and Cell Biology, vol. 35, no. 6, pp. 867-880, 2003.

[105] E. L. Schiffrin, "Effects of aldosterone on the vasculature," Hypertension, vol. 47, no. 3, pp. 312-318, 2006.

[106] M. J. Meyers, G. B. Arhancet, S. L. Hockerman et al., "Discovery of (3S,3aR)-2-(3-chloro-4-cyanophenyl)-3-cyclopentyl3,3a,4,5-tetrahydro- $2 \mathrm{H}$-benzo $[g]$ indazole-7-carboxylic acid (PF-3882845), an orally efficacious mineralocorticoid receptor (MR) antagonist for hypertension and nephropathy," The Journal of Medicinal Chemistry, vol. 53, no. 16, pp. 5979-6002, 2010.
[107] T. Hasui, T. Ohra, N. Ohyabu et al., "Design, synthesis, and structure-activity relationships of dihydrofuran-2-one and dihydropyrrol-2-one derivatives as novel benzoxazin-3-onebased mineralocorticoid receptor antagonists," Bioorganic \& Medicinal Chemistry, vol. 21, no. 19, pp. 5983-5994, 2013.

[108] J. Fagart, A. Hillisch, J. Huyet et al., "A new mode of mineralocorticoid receptor antagonism by a potent and selective nonsteroidal molecule," The Journal of Biological Chemistry, vol. 285, no. 39, pp. 29932-29940, 2010.

[109] N. Schupp, P. Kolkhof, N. Queisser et al., "Mineralocorticoid receptor-mediated DNA damage in kidneys of DOCA-salt hypertensive rats," The FASEB Journal, vol. 25, no. 3, pp. 968978, 2011.

[110] D. A. Calhoun, W. B. White, H. Krum et al., "Effects of a novel aldosterone synthase inhibitor for treatment of primary hypertension: results of a randomized, double-blind, placeboand active-controlled phase 2 trial," Circulation, vol. 124, no. 18, pp. 1945-1955, 2011.

[111] J. Ménard, M.-F. Gonzalez, T.-T. Guyene, and A. Bissery, "Investigation of aldosterone-synthase inhibition in rats," Journal of Hypertension, vol. 24, no. 6, pp. 1147-1155, 2006.

[112] P. Mulder, V. Mellin, J. Favre et al., "Aldosterone synthase inhibition improves cardiovascular function and structure in rats with heart failure: a comparison with spironolactone," European Heart Journal, vol. 29, no. 17, pp. 2171-2179, 2008.

[113] W. B. Lea, E. S. Kwak, J. M. Luther et al., "Aldosterone antagonism or synthase inhibition reduces end-organ damage induced by treatment with angiotensin and high salt," Kidney International, vol. 75, no. 9, pp. 936-944, 2009.

[114] J. Menard, C. Watson, and S. Rebello, "Hormonal and electrolyte responses to the aldosterone synthase inhibitor LCI699 in sodium depleted healthy subjects," Journal of the American College of Cardiology, vol. 55, no. 10, p. A61.E583, 2010.

[115] L. Amar, M. Azizi, J. Menard, S. Peyrard, C. Watson, and P.-F. Plouin, "Aldosterone synthase inhibition with LCI699: a proofof-concept study in patients with primary aldosteronism," Hypertension, vol. 56, no. 5, pp. 831-838, 2010.

[116] A. D. Karns, J. M. Bral, D. Hartman, T. Peppard, and C. Schumacher, "Study of alsosterone synthase inhibition as an addon therapy in resistant hypertension," The Journal of Clinical Hypertension, vol. 15, pp. 186-192, 2013.

[117] V. J. Dzau, "Tissue angiotensin and pathobiology of vascular disease a unifying hypothesis," Hypertension, vol. 37, no. 4, pp. 1047-1052, 2001.

[118] R. M. Touyz and E. L. Schiffrin, "Signal transduction mechanisms mediating the physiological and pathophysiological actions of angiotensin II in vascular smooth muscle cells," Pharmacological Reviews, vol. 52, no. 4, pp. 639-672, 2000.

[119] H. Itoh, M. Mukoyama, R. E. Pratt, G. H. Gibbons, and V. J. Dzau, "Multiple autocrine growth factors modulate vascular smooth muscle cell growth response to angiotensin II," The Journal of Clinical Investigation, vol. 91, no. 5, pp. 2268-2274, 1993.

[120] M. J. Pollman, T. Yamada, M. Horiuchi, and G. H. Gibbons, "Vasoactive substances regulate vascular smooth muscle cell apoptosis: countervailing influences of nitric oxide and angiotensin II," Circulation Research, vol. 79, no. 4, pp. 748-756, 1996.

[121] J. B. Park and E. L. Schiffrin, "Small artery remodeling is the most prevalent (earliest?) form of target organ damage in mild essential hypertension," Journal of Hypertension, vol. 19, no. 5, pp. 921-930, 2001. 
[122] S. Oparil and E. Haber, "The renin angiotensin system. I," The New England Journal of Medicine, vol. 291, no. 8, pp. 389-401, 1974.

[123] S. Oparil and E. Haber, "The renin angiotensin system (Second of two parts)," The New England Journal of Medicine, vol. 291, no. 9, pp. 446-457, 1974.

[124] R. Morishita, G. H. Gibbons, N. Tomita et al., "Antisense oligodeoxynucleotide inhibition of vascular angiotensin- converting enzyme expression attenuates neointimal formation: evidence for tissue angiotensin-converting enzyme function," Arteriosclerosis, Thrombosis, and Vascular Biology, vol. 20, no. 4, pp. 915-922, 2000.

[125] S. J. Watkins, G. M. Borthwick, R. Oakenfull, A. Robson, and H. M. Arthur, "Angiotensin II-induced cardiomyocyte hypertrophy in vitro is TAK1-dependent and Smad2/3-independent," Hypertension Research, vol. 35, no. 4, pp. 393-398, 2012.

[126] Y. Maejima, H. Okada, G. Haraguchi et al., "Telmisartan, a unique ARB, improves left ventricular remodeling of infarcted heart by activating PPAR gamma," Laboratory Investigation, vol. 91, no. 6, pp. 932-944, 2011.

[127] V. J. Dzau, K. Bernstein, D. Celermajer et al., "The relevance of tissue angiotensin-converting enzyme: manifestations in mechanistic and endpoint data," American Journal of Cardiology, vol. 88, no. 9, pp. 1L-20L, 2001.

[128] T. Yamada, T. Kondo, Y. Numaguchi et al., "Angiotensin II receptor blocker inhibits neointimal hyperplasia through regulation of smooth muscle-like progenitor cells," Arteriosclerosis, Thrombosis, and Vascular Biology, vol. 27, no. 11, pp. 2363-2369, 2007.

[129] J. S. Powell, J.-P. Clozel, R. K. M. Müller et al., "Inhibitors of angiotensin-converting enzyme prevent myointimal proliferation after vascular injury," Science, vol. 245, no. 4914, pp. 186$188,1989$.

[130] O. Yoshida, H. Hirayama, M. Nanasato, T. Watanabe, and T. Murohara, "The angiotensin II receptor blocker candesartan cilexetil reduces neointima proliferation after coronary stent implantation: a prospective randomized study under intravascular ultrasound guidance," American Heart Journal, vol. 149, no. 1, pp. e2-e6, 2005.

[131] S. Peters, B. Götting, M. Trümmel, H. Rust, and A. Brattström, "Valsartan for prevention of restenosis after stenting of type b2/c lesions: the val-prest trial," Journal of Invasive Cardiology, vol. 13, pp. 93-97, 2001.

[132] H. Kosuge, T. Ishihara, G. Haraguchi et al., "Treatment with telmisartan attenuates graft arteriosclerosis in murine cardiac allografts," Journal of Heart and Lung Transplantation, vol. 29, no. 5, pp. 562-567, 2010.

[133] D. Gómez-Garre, J. L. Martín-Ventura, R. Granados et al., "Losartan improves resistance artery lesions and prevents CTGF and TGF- $\beta$ production in mild hypertensive patients," Kidney International, vol. 69, no. 7, pp. 1237-1244, 2006.

[134] M. Sonoda, T. Aoyagi, K. Takenaka, K. Uno, and R. Nagai, "A one-year study of the antiatherosclerotic effect of the angiotensin-II receptor blocker losartan in hypertensive patients: a comparison with angiotensin-converting enzyme inhibitors," International Heart Journal, vol. 49, no. 1, pp. 95-103, 2008.

[135] C. G. Brilla, L. S. Matsubara, and K. T. Weber, "Antifibrotic effects of spironolactone in preventing myocardial fibrosis in systemic arterial hypertension," American Journal of Cardiology, vol. 71, no. 3, pp. 12A-16A, 1993. 


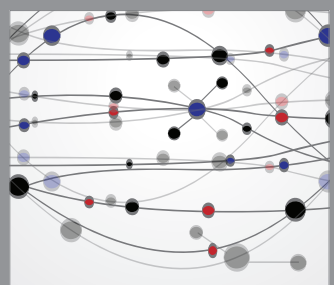

The Scientific World Journal
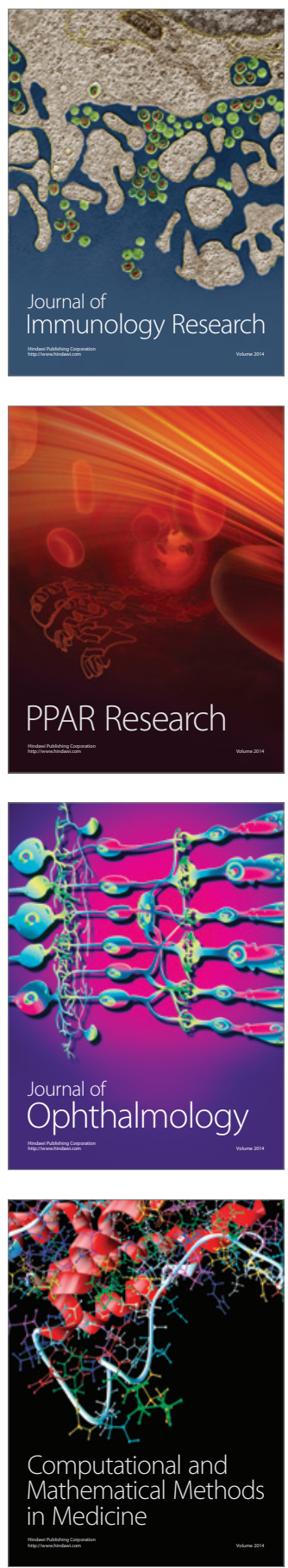

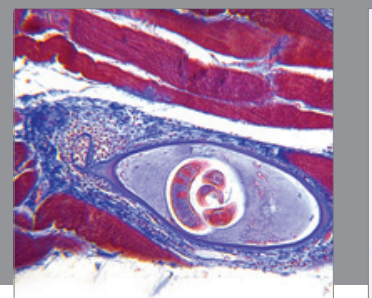

Gastroenterology

Research and Practice
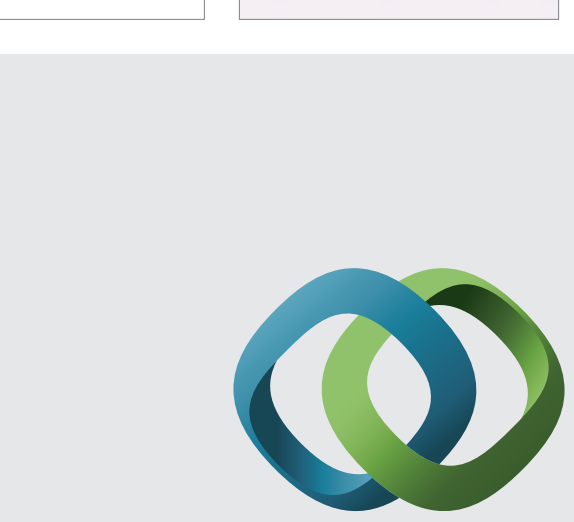

\section{Hindawi}

Submit your manuscripts at

http://www.hindawi.com
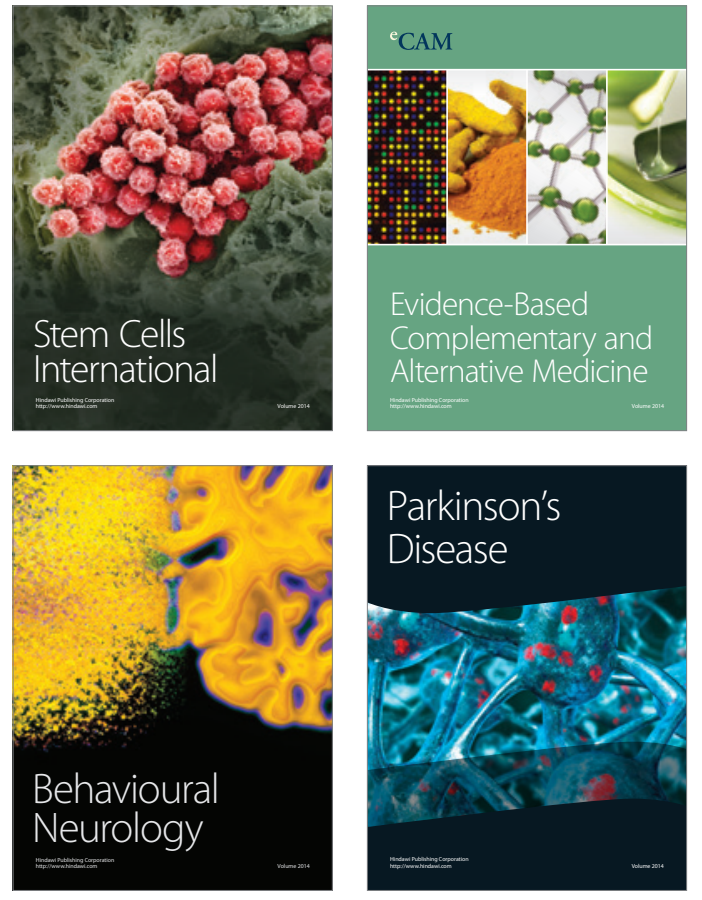
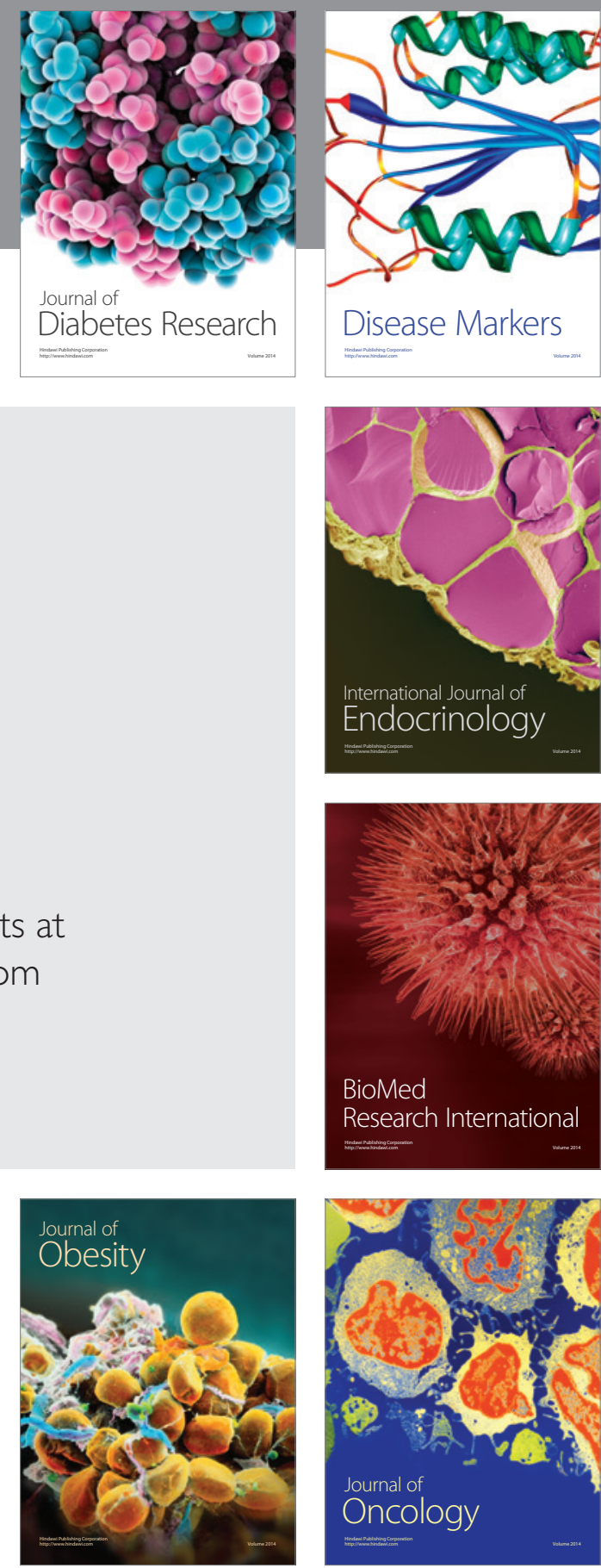

Disease Markers
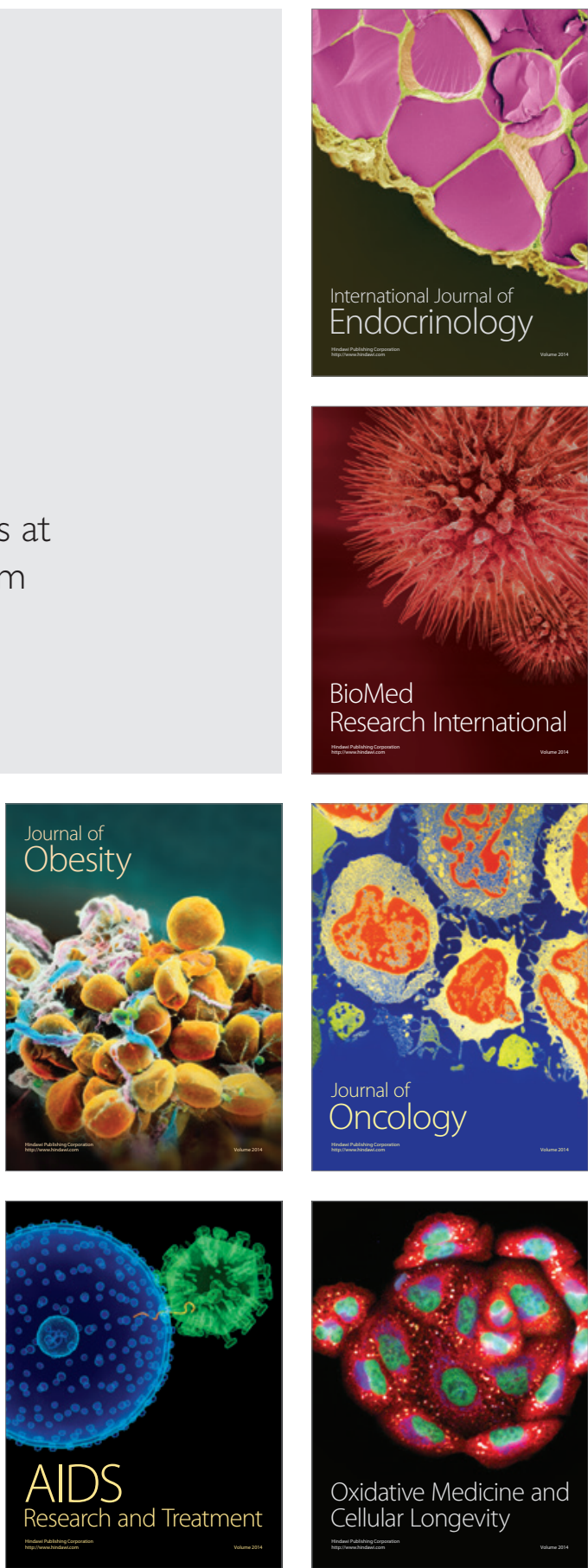